\title{
Social well-being of elderly people (based on the survey results)
}

\author{
Lubov Ivankina $^{1, a}$, Vera Ivanova ${ }^{1,2}$ \\ ${ }^{1}$ Tomsk Polytechnic University, 634050 Lenin Avenue, 30, Tomsk, Russia \\ ${ }^{2}$ Tomsk State University, 634050 Lenin Avenue, 36, Tomsk, Russia
}

\begin{abstract}
The paper presents the study of the problem of social well-being of elderly people and analyses the outcome of appraisals given by elderly people to their own health and health maintenance activities. Basing on the sociological tradition of studying a social well-being and health phenomenon, the authors have identified the peculiarities of social practices of elderly people living in Tomsk Oblast and correlated social well-being of elderly people with their own health appraisals. The paper gives the survey results (the sample included 400 persons) that allow evaluating the degree of satisfaction with life, health, material status, social activity and identifying life preferences, values and orientations of the elderly in Tomsk Oblast. During the problem studying the hermeneutical approach and the methods of comparative analysis and mathematical statistics were applied.
\end{abstract}

\section{Introduction}

The interest in the problem of social well-being of elderly people originates from the changes happening in the modern society and, primarily, in a fast growing tendency of population ageing. The mentioned tendency influences the socioeconomic systems of the countries worldwide, including such systems as labour-market, the markets of employment and income, and consumer market, as well as social funds, national policy, legislation, infrastructure, social relations and other elements.

Elderly people are now getting the status of significant economic and political agents whose interests, preferences and decisions define not only their own lives but also the development prospects of global economy as a whole.

Another important tendency in modern research development is studying not so much objective economy and society development indicators as subjective expectations and preferences, the aggregation of which allows obtaining a more comprehensive view of the reality through the prism of subjects' attitude to it. The described approach significantly complements traditional scientific research while it enables giving an estimate not only to the world around but also to the human's position in it.

The concern of elderly people about their well-being is closely connected to their health state. Social significance of a person's attitude to his/her own health is caused by a number of reasons. Growing older, people's health deteriorates and it becomes more difficult to keep well-being at a high level and take a

\footnotetext{
a Corresponding author: ivankina@tpu.ru
}

thorough care of health. The increase of the number of fee-based medical services and the reduction of free medical treatment force people to alter their attitude to health by taking responsibility and care of their own health. According to Russian Public Opinion Research Center "WCIOM" there is a decrease in the number of people who address doctors in case of illnesses from $32 \%$ in the year 2012 to $25 \%$ in the year 2014 . $32 \%$ of Russians self-medicate [1].

Thus, there arises the question concerning the activities providing elderly people with health care: What behavioural patterns do they largely use and how does it influence their social well-being?

The term "social well-being" means individual's (group's) satisfaction with one's own social status, welfare, living standard and life quality. Social wellbeing reflects an individual's general satisfaction with the environment, activities he/she is involved in and possessions. This is not a complete list of factors influencing social well-being. People desire to stay healthy, active and be able to cope with the challenges of the world around, reach their own goals, understanding, support and friendly attitude of other people, as well as to have confidence in the future.

The given aspects of social well-being were studied by means of the survey, conducted in Tomsk Oblast in April, 2015. The survey was conducted by Lifelong Wellbeing Lab (International Scientific Educational Laboratory for the Improvement of Wellbeing Technologies of Older Adults), created within the implementation of the project on the scientific research "Evaluation and improvement of social, economic and emotional wellbeing of elderly people" on the basis of 
the Department of Economics, Tomsk Polytechnic University.

The method of questionnaire distribution was used for surveying 400 people. The research was conducted with the use of a stratified multistage sample. For the sample computation, the results of The Russian Census, 2010, were used. At the first stage the sampling units were represented by regions and towns of Tomsk Oblast, at the second one - by every third and fourth household. In terms of location, several towns (Tomsk, Seversk, Asino) and rural areas (Asinovsky, Kargasoksky, Teguldetsky and Tomsky districts) were covered during the study. Sex structure of population reflects an overall situation in Russia - the proportion of elderly men to women is $1: 2$.

\section{Socio-demographic survey results}

The subject of research is elderly people (aged 55 and older) living in Tomsk and Tomsk Oblast. Considering the specificity of early retirement of people having special working conditions, there was allocated a group of respondents younger than 55 , who made $0.3 \%$ of the general sample (400 people).

Elderly people possess all characteristics of sociodemographic communities. It is a relatively stable union of individuals, based on age, a natural demographic characteristic, having similar living conditions and environments, lifestyles, value systems and interests realized to a certain degree. This union was formed under the influence of objective social processes. This definition was the basis of forming a sample for the survey.

The gender-based sample is represented by $64 \%$ of women and $36 \%$ of men. The survey comprises three age groups of elderly people: "senior people" (from 55 to 64 years of age), which amounts to $50.5 \%$ of the whole number of respondents, "old people" (from 65 to 74 years of age), which is $30.5 \%$ and "older people" (75 years and older) $-19 \%$. According to the educational level, the respondents are distributed as follows: a considerable number of respondents $(40 \%)$ are professionally educated; every third respondent has higher or incomplete higher education; $21 \%$ - secondary education; $9 \%$ - incomplete secondary education and $0.8 \%$ of respondents have a scientific degree.

At the time of survey two thirds of respondents were out of work, one third had work and the absolute majority of them (91\%) worked full-time on a permanent basis; a small minority (1\%) had seasonal employment only for some periods (berrying, mushroom picking, etc.). The respondents' professional sphere and status before the retirement appeared to be as follows: $32 \%$ were specialists; $30 \%$ - workers (rural workers); every fifth was a white-collar worker; $9 \%$ - executives.

About a half of the respondents (48\%) are officially married and live together with spouses; 3\% live with their partners without being officially married; only $3 \%$ of respondents have never been married; $31 \%$ were widows (widowers); $14.6 \%$ are divorced and live separately.

\section{Health state self-appraisals}

The integrated index of the elderly people vitality degree (physical, mental, socio-economic states), reflected in their feelings, ideas, life satisfaction appraisals, is social well-being [2]. To evaluate various aspects of elderly people's social well-being there was used a number of variables, including attitude to the future, life satisfaction, health state self-appraisals; participation in social activities and communication.

Social well-being is the attitude of an individual to the social environment. Social well-being specifically reflects the way elderly people adapt to the changes in social reality. If an individual considers the major component of one's own attitude to life to be optimism and hope for the future, social well-being tends to be rather good and it indicates successful adaptation (adjustability) to social conditions. If, however, an individual is subjected to anxiety, insecurity and even fear, his/her social well-being and adjustability are rather poor. It leads to the following supposition: the better well-being of elderly persons is (i.e. the more confidently they follow their plans for the future), the more adaptable their behavior is, the better general, physical and mental states they have. And vice versa, there is a greater part of elderly people who undervalue their indicators of health and quality of life in general. Among such respondents there are those who are anxious and unconfident.

An important role in the structure of elderly people social well-being is played by health and health state contentment, according not only to sociologists and diverse research results [3], but also to the opinion of survey respondents, as $85 \%$ of respondents stated that the most important thing in their lives is good health. As a matter of fact, this assertion is legitimate in case if the quality of life, an opportunity to participate in different social activities directly depend on health state not only in relation to elderly people but to the disabled of any age as well.

The term "health" is a rather complex one. Russian and foreign medicine bases upon the definition given by the World Health Organization: "Health is a state of complete physical, mental and social well-being and not merely the absence of disease or infirmity" (Preamble to the Constitution of the World Health Organization as adopted by the International Health Conference, New York, 19-22 June, 1946; signed on 22 July, 1946, by the representatives of 61 States (Official Records of the World Health Organization, no. 2, p. 100) and entered into force on 7 April, 1948) [4]. From a sociological point of view, there exist the following approaches: a nature-centered approach, which considers people's health as a form of adaptation to environment; a sociocentered approach based on the interconnections of health with working conditions and rest, group and social living conditions; an anthropocentric approach connecting the definition of health with an individual's behaviour, his/her goals and life style, as well as the attitude to one's own health. The given piece of work 
deals with the anthropocentric approach, while it allows paying attention to how the individual attitude to health is revealed [5].

What is the degree of health satisfaction of the elderly respondents? Regardless of the respondents' places of living and gender, $15 \%$ of respondents consider their health to be in good (or very good) condition; more than a half (59\%) - in average (neither good, nor bad) condition; the significant part (every forth) is not satisfied with the health condition and considers it to be poor or very poor.

During the data analysis there was discovered a paradox: the respondents were not satisfied with their health condition but, at the same time, they rarely addressed doctors. Every fourth respondent had recently addressed a doctor only once a year and $21 \%$ did not address doctors. And $27 \%$ of the respondents had a rather stable situation concerning obtainment of medical care (monthly visits to polyclinic).

The reason of such situation could be rather strong health of the respondents and absence of necessity to ask for medical support. However, the significant part of the respondents has various chronic diseases: heart and musculoskeletal disorders $(57 \%$ and $48 \%$, correspondingly); almost every third respondent has gastrointestinal tract and neuralgic diseases.

According to the respondents, the main causes of health problems (chronic disease) are: firstly, stretching (hard) work (47\% of respondents); secondly, the quality of drinking water, air, etc. (35\%); third, seldom medical attention seeking $(21 \%)$.

There is a traditional belief that the state of health directly depends on physical activity (physical drill and exercises, etc.). Following the respondents opinions the situation is quite different (Fig.1). Both groups with high and poor health state appraisals include equal amount of respondents who participate in physical activities and those who do not. Moreover, the group of respondents with poor health state appraisals contains 1.8 times more respondents who are physically active.

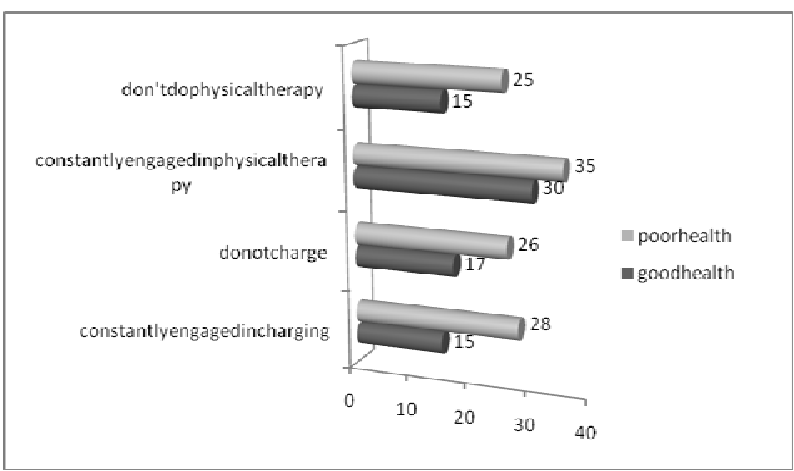

Fig. 1. Correlation of health state self-appraisals with physical activity (in percent, by groups).

One of the research aims was to define the dependence of health state self-appraisals on social wellbeing of the respondents. The diagram (Figure 2) shows that the group of respondents with optimistic attitude to life presents 1.5 times greater amount of positive health state self-appraisals. And, conversely, the group of respondents with pessimistic attitude to life contains 7 times larger amount of those who consider their health state to be poor.

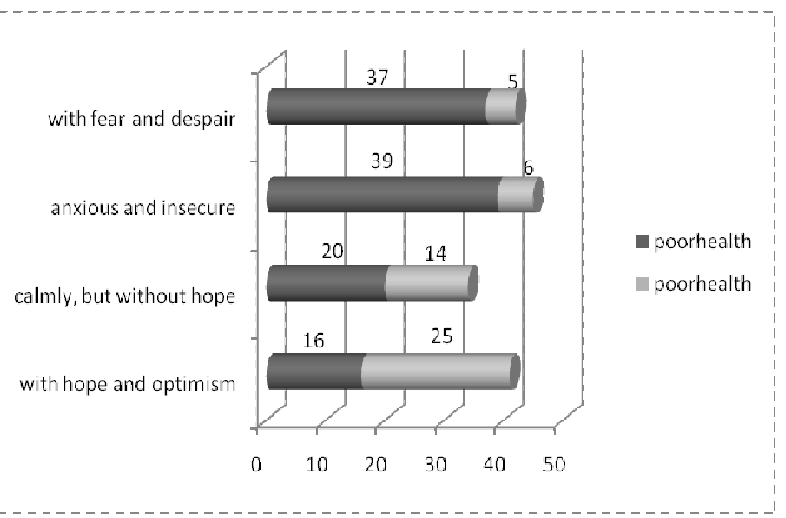

Fig. 2.Dependence of respondents' health state self-appraisals on well-being (in percent by groups)

Thus, the relationship between health state selfappraisals and emotional well-being of elderly people has been educed. The respondents having an optimistic view of the future chose positive alternatives in their health state self-appraisals, while those ones with a pessimistic view of life chose low and negative marks.

\section{Life satisfaction}

In what way are life perspectives evaluated with ageing? What attitude do elderly people have to their future? Totally, the majority of respondents $(70 \%)$ perceive future perspectives in an affirmative way, while one third of these people view the perspectives with optimism and hope, $40 \%$ - in a calm way, though not having any strong expectations. On the other hand, there is a significant number of respondents who feel doubt about their future - every fifth experiences anxiety and uncertainty, $5 \%$ face their future with fear and despair.

The number of elderly people, feeling despondency and belonging to the group with an affirmative view of the future, was equal to $25 \%$, only $2 \%$ of whom had this feeling constantly. $63 \%$ of respondents, belonging to the group of elderly people and viewing their future with fear and despair, experienced despondency at the moment of conducting the survey; $16 \%$ of them have such feeling constantly.

In the group of respondents with an optimistic attitude to the future there are 2 times less individuals feeling despondency in comparison to the group of respondents who abandoned all hope and had a destructive attitude to life.

The relationship between those, who evaluate the quality of life with emotional disposition, has been educed and is presented in Table 1 . 
Table 1. Respondents' evaluation of material status in terms of their attitude to life (in percent, by groups).

\begin{tabular}{|l|c|c|c|}
\hline $\begin{array}{l}\text { Evaluation of } \\
\text { material } \\
\text { status }\end{array}$ & $\begin{array}{l}\text { All } \\
\text { respondents }\end{array}$ & $\begin{array}{l}\text { Respondents } \\
\text { with an } \\
\text { affirmative } \\
\text { view of the } \\
\text { future }\end{array}$ & $\begin{array}{l}\text { Respondents } \\
\text { feeling fear } \\
\text { and despair }\end{array}$ \\
\hline $\begin{array}{l}\text { I can buy } \\
\text { everything I } \\
\text { want }\end{array}$ & 2 & 2,5 & - \\
\hline $\begin{array}{l}\text { I can buy a } \\
\text { lot of things } \\
\text { but cannot } \\
\text { afford major } \\
\text { purchases }\end{array}$ & 23 & 30,5 & 16 \\
\hline $\begin{array}{l}\text { I can buy } \\
\text { new clothes } \\
\text { and shoes }\end{array}$ & 32 & 32 & 16 \\
\hline $\begin{array}{l}\text { I spend all } \\
\text { income on } \\
\text { buying food }\end{array}$ & 41 & 34 & 58 \\
\hline $\begin{array}{l}\text { I have not } \\
\text { enough } \\
\text { money to } \\
\text { buy food }\end{array}$ & 2 & 1 & 10,5 \\
\hline
\end{tabular}

It is fair to assume that material status appraisals are connected with people's real income rather than with their attitude to life. But it is not quiet this way, and figure 3 shows the correlation of the respondents' real income and their attitude to life.

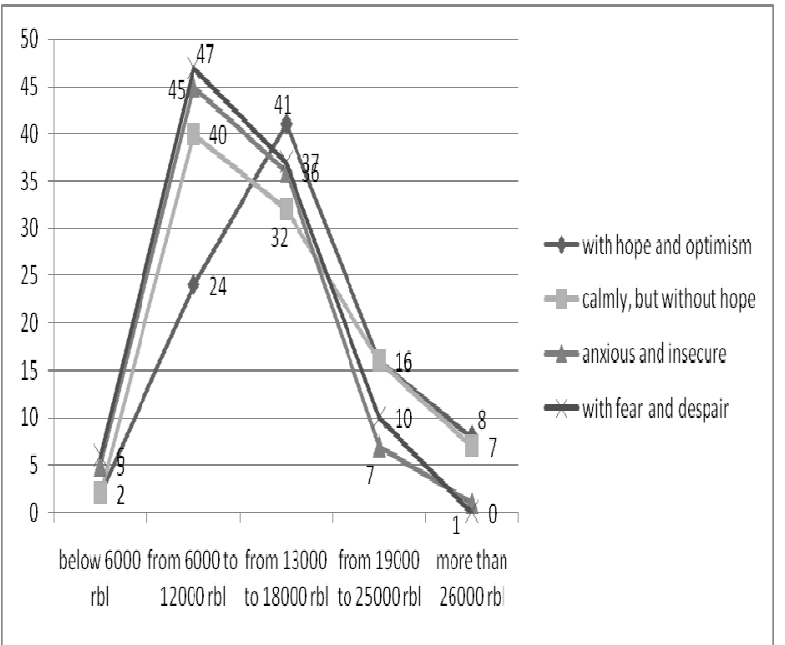

Fig. 3. The correlation between respondents' real income and their attitude to life (in percent, by groups).

The graphs data testify that the groups of respondents with different income include both optimists and pessimists. The group of the respondents with the monthly income equal to not less than 6000 rubles includes both optimists and pessimists. There are a number of discrepancies found but they seem to be not as significant as we could expect. Serious discrepancies in evaluating the disposition are discovered in the group of elderly people with a rather high income (from 6000 rubles to 12000 rubles). In this cluster, there are almost
2 times more hopeless respondents than those, who look affirmatively to their future.

One of the research suppositions was to test the correlation between elderly people's well-being and the frequency of communication with close people (relatives and friends). The vast majority of the respondents communicate over the telephone, only $0.3 \%$ of respondents do not use a telephone as a means of communication; notably, $65 \%$ of respondents talk over the telephone every day. The second way of interaction in the order of importance is personal meetings. Only $0.2 \%$ of respondents do not meet with other people and $35 \%$ of elderly people have personal meetings on a daily basis. Elderly people scarcely use social networks for communication; only $7.5 \%$ interact with their close people via the Internet on a daily basis and $11 \%$ several times a week. $91 \%$ of respondents do not visit membership clubs (health groups, etc.).

Regardless of the frequency and form of interaction the respondents had positive and negative views of life in equal proportion (Table 2).

Table 2. Frequency and form of interaction regardless of the type of the own future perception (in percent, by groups).

\begin{tabular}{|l|l|l|l|l|}
\hline \multicolumn{1}{|c|}{ Forms } & \multicolumn{2}{c|}{$\begin{array}{c}\text { Personal } \\
\text { meetings }\end{array}$} & \multicolumn{2}{c|}{$\begin{array}{c}\text { Communication } \\
\text { by the phone }\end{array}$} \\
\cline { 2 - 5 } Disposition & Daily & Never & Daily & $\begin{array}{c}\text { Neve } \\
\mathrm{r}\end{array}$ \\
\hline Optimistic & 32 & 2 & 69 & 1 \\
\hline $\begin{array}{l}\text { Calm but } \\
\text { hopeless }\end{array}$ & 36 & 1 & 62 & 0 \\
\hline $\begin{array}{l}\text { Anxious and } \\
\text { uncertain }\end{array}$ & 33 & 0 & 68 & 1 \\
\hline $\begin{array}{l}\text { With fear and } \\
\text { despair }\end{array}$ & 42 & 0 & 74 & 0 \\
\hline
\end{tabular}

Thus, every third respondent with no regard to the level of social well-being has daily personal meetings with other people, and $42 \%$ of respondents from the group of anxious and uncertain individuals do the same. Similar situation concerns communication by the phone but there are twice more respondents who use this form of communication. Consequently, there is no link between the elderly people communication frequency and their social well-being. However, the following correlation between the communication frequency and disposition is induced: the more negative emotions an individual has, the more communication he/she needs.

\section{Priorities and major values in elderly people's lives}

What is the most important for elderly people? The survey results show that the elderly people values hierarchy is as follows: the most important is the welfare of close people $(87 \%)$; the second value is good health (85\%); thirdly, they mentioned material wealth $(50 \%)$ and the need for communication (48\%); the next level of hierarchy is represented by satisfactory living conditions $(25 \%)$ and governmental support and care $(23 \%)$. The subsequent layer is occupied by an interesting job (17\%) 
and the last of the listed values is the need for proactive life attitude $(7.5 \%)$.

According to the majority of respondents, it is possible and necessary to trust other people. The percentage of people who agree with the given statement is equal to $75 \%$, while every fourth considers trusting other people as impossible.

How do elderly people assess their importance in society, ability to affect young generation? Two thirds of the respondents suppose that the older generation influences morality and social environment of the society. The remaining part is sure that the youth do not regard their opinions and consider that the cause of such behaviour of young people is peers' influence. This factor is rather conventional in the generation gap and it influences the delivery of traditional notions into the modern ones, the majority indicates the conservatism and lack of desire to adapt to the altering conditions with the aim to stay modern and relevant for the new generation.

The degree of congeniality between generations is largely defined by the frequency and forms of mutual help of children and elderly people and by the presence or lack of informal and emotional communication. Relations with close people and relatives are satisfactory for the absolute majority of respondents (91\%), 7\% defined them as neutral and only $1 \%$ - as negative.

Inter-generational bounds are revealed in diverse forms of help exchange between generations. The percentage of elderly people who help other people is equal to $89 \%$ according to the research results, two thirds of these people are ready to help everyone who needs help, and $28 \%$ of respondents help their close people and relatives. Help is given every day or one or two times a week.

Individuals' activity and responsibility are the significant factors of their social well-being. Almost half of the respondents (45\%) make decisions on their own and practically the same number $(47 \%)$ rely on the opinion of their family. Almost nobody takes into account friends' opinions except $4 \%$ of respondents, only $0.5 \%$ address social services and $0.5 \%$ find it difficult to comment on the point.

The vast majority of respondents do not need any assistance provided by social services (repairs, nursing, shopping, cooking, etc.). The percentage of elderly people requiring help is within 1 to $2 \%$. Elderly people count on themselves and their relatives. According to the results of the survey conducted, $81 \%$ of respondents are assisted by their relatives with household chores. The role of neighbours and social workers is minor, only $6 \%$ of respondents ask neighbours and friends for help, and $0.5 \%$ - address social services.

\section{Conclusion}

According to the research results, welfare of elderly people is the equivalent to life quality and is largely connected with their social well-being, which is defined by the following variables: life perspectives evaluation, attitude to life, health self-appraisal, involvement into social communication. Elderly people well-being is mainly connected with their disposition, emotional state, which, in their turn, largely depend on the material part. Notably, the material state implies not their real income but their level of aspiration and vision of welfare. Furthermore, life perspectives define the ratio scales of other variables, such as attitude to life (positive/negative), health self-appraisal, and life satisfaction.

\section{Acknowledgment}

This work was performed by the authors in collaboration with Tomsk Polytechnic University within the project "Evaluation and Enhancement of Social, Economic and Emotional Wellbeing of Older Adults" under the Agreement No.14.Z50.31.0029.

\section{References}

1. How to save health? WCIOM press release № 2600 (2014). Retrieved from: http://wciom.ru/index.php?id=268\&uid=114851

2. W.C. Cockerham, Health Lifestyle Theory and the Convergence of Agency and Structure // Journal of Health and Social Behavior. V. 46. № 1 (2005)

3. R. Veenhoven, Sociological theories of subjective well-being // M. Eld, R. Larsen (eds) The Science of subjective Well-being: a Tribute to Ed Diener. New York: Guilford Publications (2008)

4. Constitution of the world health organization. Retrieved from: http://docs.cntd.ru/document/901977493

5. V.A. Kiselev, Health attitudes strategies // Social work and nursing care in public healthcare system: problems of professional activities and innovations in personnel training. Yekaterinburg (2009). Retrieved from: http://do.teleclinica.ru/375092/ 